\title{
A HYBRID SIMULATION MODEL FOR LARGE-SCALED ELECTRICITY GENERATION SYSTEMS
}

\author{
Marco Pruckner \\ Reinhard German \\ Computer Networks and Communication Systems \\ University of Erlangen-Nuremberg \\ Martensstr. 3 \\ 91058 Erlangen, GERMANY
}

\begin{abstract}
Due to the transition towards a sustainable energy supply, many electricity generation systems are faced with great challenges worldwide. Highly volatile renewable energy sources play an important role in the future electricity generation mix and should help compensate the phase-out of nuclear power in countries such as Germany. Simulation-based energy system analyses can support the conversion into a sustainable future energy system and are intended to find risks and miscalculations. In this paper we present models for the main components of the electricity generation system. We use a hybrid simulation approach with system dynamics and discrete event modules. This modular design allows quick model adoptions for different scenarios. Simulation results show the development of the future annual electricity balance, $\mathrm{CO}_{2}$ emission balance, electricty imports and exports, and the wholesale price of electricity.
\end{abstract}

\section{INTRODUCTION}

Many electricity generation systems all over the world will be faced with a high penetration of electricity generated by renewable energy sources (RES) in the future. For instance, the Australian Government aims to ensure that the equivalent of at least $20 \%$ of Australia's electricity will come from RES by 2020 (Australian Government 2013). The European Union enacted the "climate and energy package" in 2009 (Commission of the European Communities 2008). This policy specifies key objectives such as raising the total share of EU energy consumption generated by RES to $20 \%$ and reducing EU greenhouse gas emissions by $20 \%$ from 1990 levels. Especially for Germany the RES targets are even stronger. In 2020, $35 \%$ of Germany's electricity should be covered by RES. Additionally, the phase-out of nuclear power leads to an even bigger challenge for the electricity generation system of Germany.

The German federal state Bavaria is particularly affected: in 2010, more than $50 \%$ of the Bavarian electricity consumption was provided by nuclear power, whereas in Germany as a whole the share generated by nuclear power was only $22 \%$ (Dena - German Energy Agency 2012a). In order to handle the energy transition, the Bavarian state government passed an energy concept (Bavarian State Government 2011), saying that in $202150 \%$ of the Bavarian electricity demand should be covered by RES.

Due to the phase-out of four nuclear power plants in the next ten years, there will be a lack of approximately $5 \mathrm{GW}$ of guaranteed capacity for electricity generation in Bavaria in 2023. In addition, a number of gas and oil power plants achieve their technical lifespan in the next ten years, i.e., further power plants with a guaranteed capability of approximately $2 \mathrm{GW}$ will be disconnected from the grid (Bundesnetzagentur 2013). On the other hand, a high amount of variable and not always guaranteed electricity generated by RES must be integrated with established energy systems. Also the building of new effective combined cycle gas turbines should help to compensate the nuclear phase-out. Simulation-based 


\section{Pruckner and German}

energy system analysis model the most relevant parts of complex electricity generation systems in order to come closer to its understanding, to provide a tool for the investigation of various scenarios, to find risks and miscalculations, and finally to support the conversion into a sustainable future electricity generation system.

In this paper we present a flexible, validated, and efficient simulation model to investigate electricity generation systems on a larger scale. For this purpose, basic components of electricity generation systems, such as conventional power plants, fluctuating RES (wind turbines, solar panels, hydropower stations), aggregated demand profiles, and storage facilities are provided. Moreover, we are taking political (e.g., feed-in of RES has priority over conventional ones) and economic constraints (e.g., marginal costs of conventional power plants) into account. The implementation of a simple forecast model provides the investigation of control power. Basic components can be connected in various ways to analyze different electricity generation mix strategies (especially for the German federal state Bavaria). The particular situation in Bavaria motivated us to develop such a model, but due to its modular design, the model can be applied to any other region of the world.

Previous versions of our simulation model have already been used to analyze the importance of the extension of energy storage facilities (Pruckner, Bazan, and German 2012), the development of full load hours of newly constructed gas power plants (Hassmann, Pruckner, and German 2013), or the behavior of the residual load (defined as the difference between electricity demand and the amount supplied by RES) in the future (Pruckner and German 2013). However, the applied methodological backround and the hybrid simulation approach are not presented in detail in these publications.

The model is a hybrid simulation model: Due to the penetration by highly volatile RES and the complex situation to cover the electricity supply at all times, simulation was identified as an appropriate tool. We apply the commercial simulation tool AnyLogic 6 (XJ Technologies Company Ltd. 2013) which allows to combine System Dynamics (SD) and Discrete-Event Simulation (DES) in one framework. SD-Models represent continous processes such as energy flows, i.e., the energy exchange between different components. DES is used for control decisions, e.g., final shutdowns of nuclear power plants. Components are active objects with internal SD and discrete event parts.

A main contribution of this paper is a modeling approach for different components of electricity generation systems. Thereby, we explain the hybrid simulation approach on the basis of conventional power plants in detail. A second contribution is the modeling of the interaction of conventional power plants, fluctuating RES, volatile demand, electricity imports and exports, and storages under consideration of political and economic constraints. Moreover, this paper contributes an investigation of four different scenarios and simulation results with regard to the development of the electricity generation balance and $\mathrm{CO}_{2}$ emission balance.

The remainder of the paper is organized as follows. In section 2 we discuss related work. Section 3 presents basic concepts used in our simulation framework. Section 4 describes the modeling of basic modules. In section 5 we define different scenarios, whereas section 6 presents simulation results. Section 7 concludes the paper.

\section{RELATED WORK}

There are many publications in the field of hybrid simulation techniques. An overview of different simulation paradigms and the combination of them is given in Heath et al. (2011). The idea of combining different simulation paradigms into one common environment is applied in various domains. For instance, there are academic publications on hybrid simulation models for problems in the healthcare domain. Djanatliev et al. (2012) presented a hybrid simulation environment with SD and agent-based models (ABM) to indicate the effects of new innovations within a healthcare system. Zulkepli, Eldabi, and Mustafee (2012) use the combination of SD and DES to model integrated care systems in healthcare.

There are also serveral publications of hybrid simulation models with applications in the energy sector. In (Bazan and German 2012) the authors describe a SD-DES approach for the analysis of a grid of 


\section{Pruckner and German}

domestic homes equipped with different technological options such as solar modules, micro combined heat and power systems, and electricity storages. Boulaire et al. (2012) combine ABM and particle swarm optimization (PSO) to provide a decision tool for planning future distribution networks with a high amount of decentralized electricity generators.

Literature pertaining to electricity generation systems relevant to the subject of this paper is focussed on the analysis of different scenarios under socio-ecnomic conditions (Schlesinger et al. 2010). A consideration of the dynamic growth of electricity generated by RES or a high amount of energy storage opportunities are not taken into account. In (Blesl et al. 2011) the authors analyzed the economical and environmental effects of the phase-out of nuclear power in Germany. The German Renewable Energies Agency (2010) investigated the compability of volatile RES and base load power plants (e.g., nuclear or lignite power plants). They came to the conclusion that RES and conventional base load power plants are incompatible. Worlwide energy forecasts are considered by the International Energy Agency (2012). They developed a tool to generate detailed sector-by-sector and region-by-region forecasts for various scenarios.

Moreover, there are further computer tools available for various analyses in the energy sector. Connolly et al. (2010) studied 37 tools that can be used to analyze the integration of RES. The tools are compared, among others, with regard to their type (simulation, optimization, etc.), availability (free to download or commercial), geographical area (local, national, wordwide), and timesteps (yearly, hourly, minutes). They came to the conclusion that there is no energy tool available that addresses all issues related to the integration of RES. In addition, the methodological backround for the calculations used in these tools, especially for commercial ones, is often not explained in detail.

The idea of this work is to present a detailed, component-based, and easily extendable simulation framework to model the most relevant aspects of electricity generation systems in an hourly resolution. With our framework it is also possible to investigate the special situation of Bavaria (high penetration by electricity generated by RES in the future, phase-out of nuclear power, building of new gas power plants, etc.). Thereby, we can also take into account possible changes of political and economic constraints. Hence, we can generate different scenarios quite simply and fastly with regard to the extension of RES and further aspects in order to investigate the annual electricity generation balance, the development of greenhouse gas emissions etc.

\section{BASIC CONCEPTS OF THE HYBRID SIMULATION FRAMEWORK}

In this section we describe the basic concepts of our simulation framework. They include the hybrid simulation approach, additional Java code blocks to take also economic and political constraints into account, and specific scenario interfaces.

\subsection{Hybrid Simulation}

Our simulation framework is built to to answer different questions about the future electricity generation system. As we consider such a complex system and its development as a whole, we implemented a framework that includes many system relevant parts on a high level.

For instance, we not only consider the phase-out of nuclear power plants at fixed time steps, the building of new gas power plants, the dynamic growth of RES, but also the annual changes in fuel prices and marginal costs, breakdowns of electricity generators, and stochastic changing forecast parameters. All these features change at discrete points in time, i.e., we use discrete events and state charts to model these control decisions. In contrast, the electricity demand, the run up and shut down of power plants, charging/discharging of electricity storages, the supply of electricity, and power flows in general are variables that change continuously with respect to time. Therfore, we use the SD simulation technique.

For realization purposes the commercial simulation tool AnyLogic 6 (XJ Technologies Company Ltd. 2013 ) is used. Due to active object classes, it supports the development of component-based simulation frameworks. For instance, Figure 1 shows the unavailability event component for electricity generators 


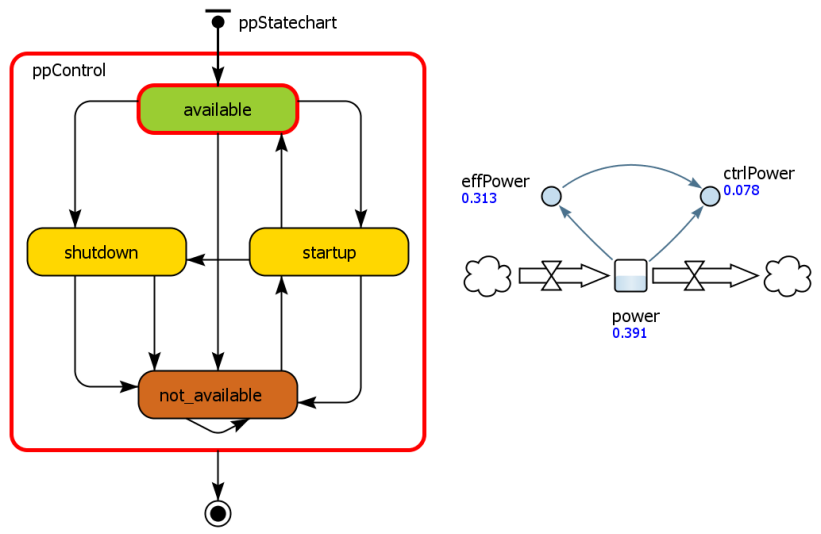

Figure 1: State chart and system dynamics model for unavailability events

which consists of a state chart model and a system dynamic model. The state chart models the current operating state of the power plant. We distinguish between four states:

- available: The power plant is available and the provider can offer electricity on the spot market.

- shutdown: The power plant is available, but due to maintenance reasons its available capability is decreasing to zero.

- not_available: The power plant is not available because of maintenance reasons or breakdowns.

- startup: The power plant is available and its available capability increases to its maximum power.

Transitions connect the different states. Every transition is triggered by messages. The state chart receives messages with the type of the unavailability event. Currently, three different types of unavailability events are implemented: partial breakdowns, total breakdowns, and maintenance. The creation of messages is explained in section 4.1.

On the right side of Figure 1 we see an example for an SD model. If the shutdown (startup) state is active the available power of the power plant decreases (increases), i.e., the states shutdown and startup affect the positive and negative flow of the SD model to control the available capability. The available capability of power plants is splitted into effPower which is offered on the spot market and ctrlPower which is reserved for providing control power. The amount of ctrlPower depends on a certain percentage of the maximum power and can be set for every power plant individually (see also section 4.1).

\subsection{Java Code Blocks}

With AnyLogic it is possible to enrich active objects by Java code blocks. We use Java to implement political and economic constraints. For instance, all conventional power plants which offer their available generation capability on the spot market are collected in a linked list of the active object type "Power Plant". This list is sorted by the marginal costs of each power plant, which depend on the current fuel price and the $\mathrm{CO}_{2}$ certificate price (for more details see section 4.1) (von Roon and Huck 2010). Thus, we are able to simulate the merit order of conventional power plants. The term merit order stands for the order in which power plants will be used to cover the electricity demand.

\subsection{Scenario Interfaces}

In order to investigate the influence of different parameters (such as the dynamic growth of RES or the annual changing fuel prices) on the electricity generation system, we implemented simple scenario interfaces with the help of table functions in AnyLogic. Figure 2 depicts an exemplary development of the $\mathrm{CO}_{2}$ certifacte 


\section{Pruckner and German}

\begin{tabular}{l} 
Table Data: \\
\begin{tabular}{|l|l|}
\hline Argument & Value \\
\hline 2010 & 7 \\
2011 & 8 \\
2012 & 8.85 \\
2013 & 9.3 \\
2014 & 9.68 \\
2015 & 13.23 \\
2016 & 16.78 \\
2017 & 20.34 \\
2018 & 23.89 \\
2019 & 27.45 \\
2020 & 31 \\
\hline
\end{tabular} \\
\hline
\end{tabular}

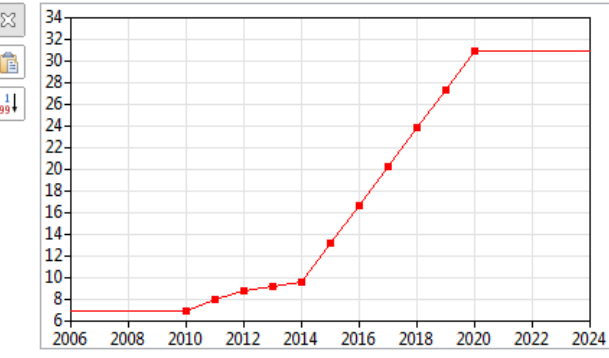

Figure 2: Table function in AnyLogic (argument: year, value: $\mathrm{CO}_{2}$ certificate price in euro per ton)

prices in euro per ton. This approach is an effective and easy way to implement different framework conditions and to study their impact on the future development of the electricity generation system.

\section{MODELING OF BASIC COMPONENTS}

In this section we describe the modeling approach of basic components of electricty generation systems. Furthermore we present the combination of all components in order to form the electricity generation system and describe the validation process for our simulation framework.

\subsection{Conventional Power Plant Module}

We developed a detailed power plant module, modeling conventional electricity producers. Figure 3 depicts as an example a gas turbine power plant based on this module.
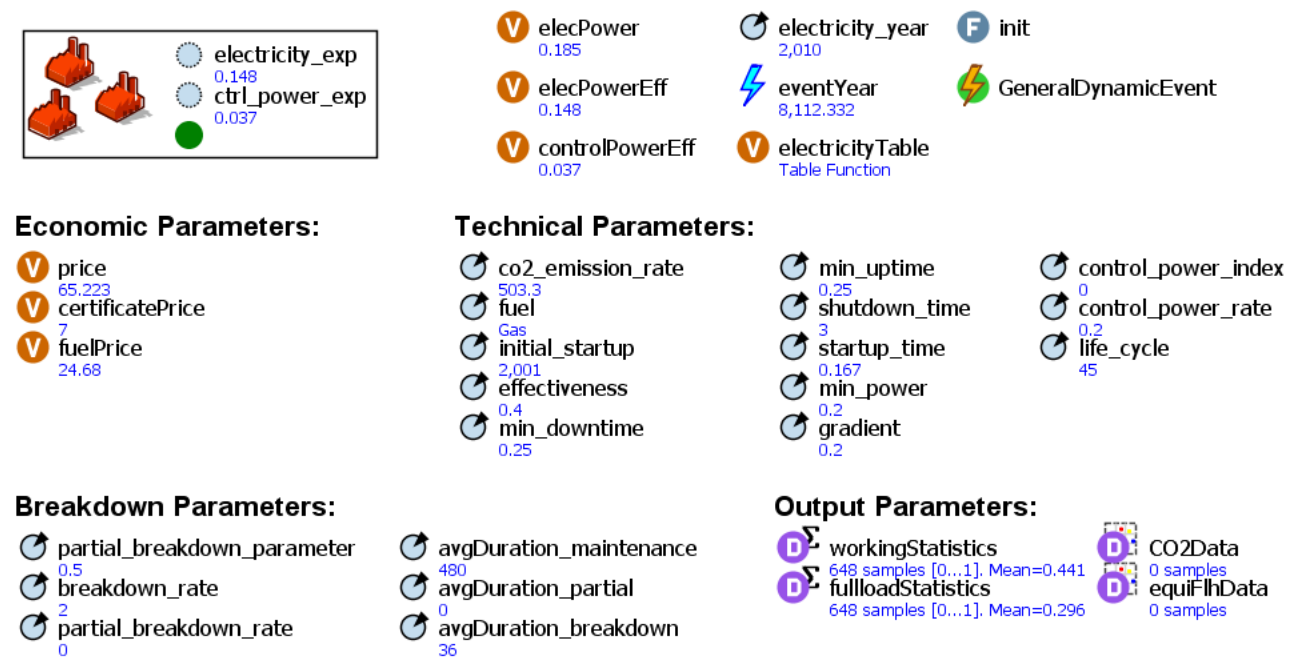

Figure 3: Power Plant Module implemented in AnyLogic

As we can see, a number of parameters regarding technical and economic properties of power plants have been implemented. Every year the cyclic event eventYear is executed. In this way we can control the lifespan-related final shutdowns of power plants and the creation of unavailability events. The eventYear event creates a uniformly distributed number of partial and total breakdown events and one maintenance event. For this we use official statistics about the annual average number of partial and total breakdowns of power plants sorted by their fuel types according to (Haubrich H.-J. and Consentec GmbH 2008). Further parameters such as the available capability after partial breakdowns, the mean number of breakdowns, 


\section{Pruckner and German}

or the average duration time of maintenance or breakdowns are also implemented. Thus, we can control unavailability events as already mentioned in section 3.1.

The parameters min_uptime, shutdown_time, and startup_time affect the duration time of the different states of the ppControl state chart (see Figure 1).

In order to take economic constraints into account, we compute for every conventional power plant the marginal costs. These costs determine the position of the power plant in the merit order. The marginal costs $M C$ are defined as $M C=\frac{p_{F u e l}}{\eta}+p_{\mathrm{CO}_{2}} \cdot \frac{E_{\mathrm{CO}_{2}}}{\eta}+p_{\text {var }}$, where $p_{\text {Fuel }}$ denotes the specific fuel price, $p_{\mathrm{CO}_{2}}$ denotes the $\mathrm{CO}_{2}$ certifacte price, $p_{v a r}$ denotes the specific operation and maintenance costs, $E_{\mathrm{CO}_{2}}$ denotes the specific $\mathrm{CO}_{2}$ emissions rate, and $\eta$ denotes the effectiveness of the power plant.

If a power plant is requested to cover the demand, the power plant has to feed-in with a minimum power (min_power parameter in percent of the maximum generation power).

The control_power_rate, and control_power_index pertain the provision of control power. In general, highly flexible power plants, such as gas turbines or combined cycle gas turbines, supply control power. The control_power_rate is a variable percentage (usually $20 \%$ ) of the maximum generation power withholding for the provision of control power. The control_power_index ascribes each power plant the position in the order of providing control power.

Every power plant active object includes also output parameters and output statistics such as working hours per year, full load hours per year, $\mathrm{CO}_{2}$ emissions in tons per year, and the number of start/stop cycles. Hence, each power plant can be investigated individually.

\subsection{Module for Renewable Energy Sources}

For the different volatile RES, such as wind energy, solar energy, hydropower, and geothermal energy, we implemented quite similar modules. Basically, we use original feed-in data of photovoltaic parks, hydroelectric power plants, and geothermal power stations (Renerco AG 2012, Ostwind Project GmbH 2012, Allgäuer Überlandwerk GmbH 2013). The photovoltaic module and wind energy module are described in (Pruckner and German 2013) in detail.

We implemented an Auto-Regressive-Moving-Average (ARMA) model to obtain a high performant wind speed generator (Kremers et al. 2009) for our wind energy module. The hourly power output of one wind energy station is generated by evaluating the associated power curve with the current simulated wind speed.

The feed-in data of solar panels and hydroelectric power plants are stored as table functions. These feed-in data are sampled and superimposed with stochastic functions to model the fluctuating behavior of the electricity generation of photovoltaic panels and hydroelectric power plants.

The available electricity generation power of geothermal power stations depends on the outside temperature (Ostwind Project GmbH 2012). Therefore, we modeled the temperature-dependent effictiveness and the daily behavior of outside temperatures by table functions. The feed-in is computed by an auxiliary depending on the current outside temperature, the availability of the geothermal power station, and the installed power.

\subsection{Demand Module}

To model the electricity demand we use official data from the ENTSO-E (2013). The ENTSO-E publishes the annual electricity consumption of different European nations in an hourly resolution. In our case the demand profiles of Germany are of particular interest. In order to achieve demand profiles for a region such as Bavaria, we scale the German ENTSO-E demand profiles to the annual electricity consumption of Bavaria. Bavaria's annual electricity consumption will be at a constant level of around $85 \mathrm{TWh}$ per year over the next ten years according to the Bavarian State Government (2011). The annual peak load demand of Bavaria is approximately $12.5 \mathrm{GW}$. 


\section{Pruckner and German}

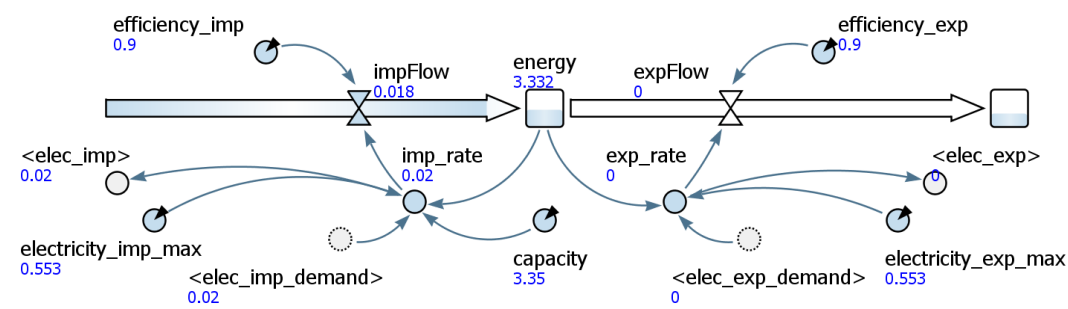

Figure 4: Model for pumped-storage hydro power stations

The ENTSO-E data records of the last four years are separated into quarters and implemented as table functions, i.e., there are four table functions for every quarter of the year available. Every quarter an event determine an uniform distributed parameter to choose a table function for the demand of the next quarter. With our approach we achieve still the aim to model hourly fluctuations and we can simulate 256 different load profiles. The scaling to an electricity consumption of $85 \mathrm{TWh}$ confirmed that the annual peak load according to the load profiles is indeed approximately $12.5 \mathrm{GW}$.

\subsection{Storage Module}

As a storage component we implemented a pumped-storage hydro power station. The charging and discharging of storage components is a continuous process. Therefore, the module is an entire SD model, shown in Figure 4. Technical features such as the degree of efficiency, maximum storage capacity, and maximum charging/discharing capability are taken into account. These properties affect the charge and discharge flows and the current fill level of the energy storage stock.

\subsection{Interaction of Basic Modules}

Now that we have an overview of all basic modules, we present the interaction between them. Due to the high complexity of electricity generation systems, there are many dependencies between the different components. For instance, the demand for conventional power plants is dependent on the feed-in of RES, i.e., beginning from a certain electricity demand at timestep $t$, we subtract the feed-in forecast of RES (Federal Ministry for the Environment, Nature Conservation and Nuclear Safety 2004) and obtain a certain residual load, which has to be covered by conventional power plants. The feed-in forecast for high volatile RES, such as wind or solar energy, are implemented by superimposing the real feed-in by a Beta-distributed parameter (Bludszuweit et al. 2008, Pruckner and German 2013). The remaining residual load is covered by conventional power plants according to the merit order already mentioned above. Because of the difference between the real and forecasted feed-in, we also take the provision of control power into account. In order to balance differences between electricity supply and demand we use pumped-storage hydro power stations and further control power mechanisms. The goal is to achieve a balanced supply and demand in every simulation step. In order to find bottleneck situations we implemented the interaction of all components by an additional SD model.

Figure 5 depicts the interaction of electricity producers, electricity demand, pumped-storage hydro power stations, and additional imports and exports. Normally, the supply should be covered by the modeled electricity producers. Surpluses and deficits should be balanced by modeled electricity storages and control power mechanism. However, this procedure is not always possible and the SD model helps to identify such bottlenecks. This is an important feature to study shortages in capacity and further imports and exports during the phase-out of nuclear power and the extension of variable electricity from RES. The numerical example in Figure 5 shows that at a certain timestep the electricity production is $10.203 \mathrm{GW}$, whereas the electricity consumption is only at a level of $10.085 \mathrm{GW}$. Therefore, storages are charged with a power of $0.118 \mathrm{GW}$. 


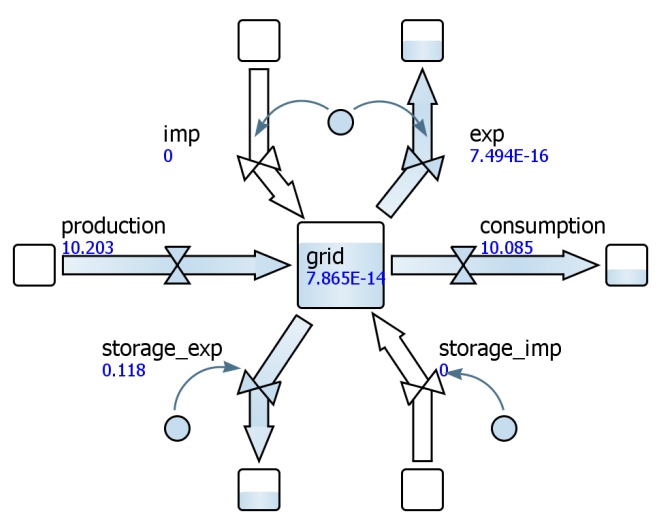

Figure 5: Interaction of electricity producers, electricity consumers, storages, and additional im- and exports

\subsection{Validation}

On the one hand we validated our model together with domain experts. We made our simulation framework transparent to them and gain their credibility. On the other hand, for the purpose of validation, we used official data for the electricity generation balance segmented into energy sources of Bavaria for the years 2010 and 2011. For our simulation model we set up the Bavarian fleet of conventional power plants and the installed power of different RES according to official data for these years (Bundesnetzagentur 2013). Furthermore, we scaled the implemented load profiles to the real annual electricity consumption of 92 TWh in 2010 and 89.2 TWh in 2011. Subsequently, we simulated the feed-in of RES and the operation of conventional power plants to cover the demand for the years 2010 and 2011 extensively in an hourly resolution and compared the results of the simulated annual mean electricity generation mix (in GWh) with the real ones.

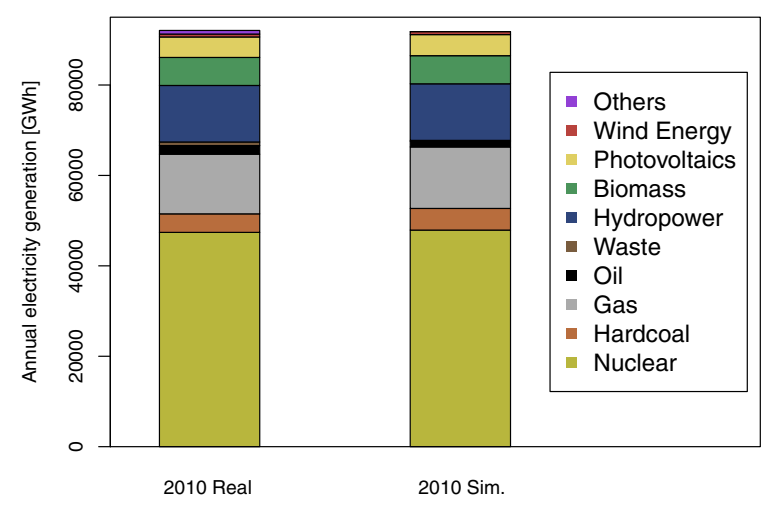

(a) 2010

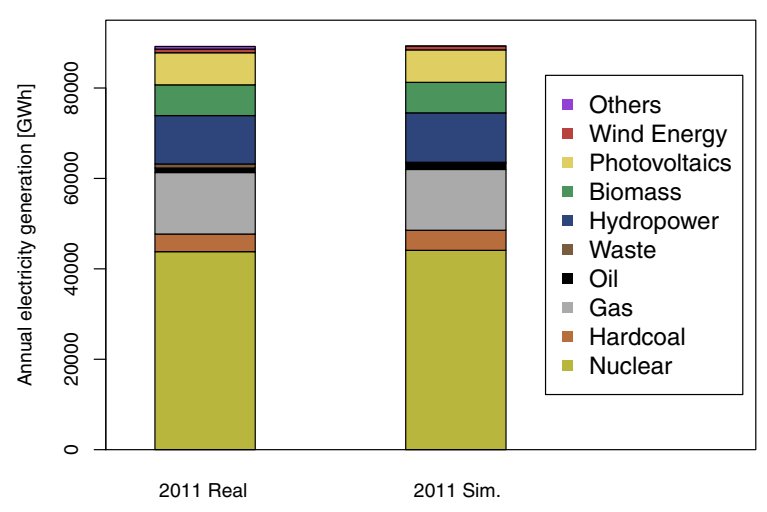

(b) 2011

Figure 6: Real and simulated electricity generation balance for validation purposes

Figure 6 shows the simulated and real electricity generation balance for the years 2010 and 2011. For RES we insert scaling factors until an overall trustworthiness has been reached.

In both 2010 and 2011 minor variations of electricity generated by conventional energy sources occur. These variations are discussed with domain experts. The main reasons are merit order effects and unavailability events of different power plants, which can distinguish from real data, because for the years 2010 and 2011 real unavailability events of power plants are not available in detail. Furthermore, oil as waste product of petroleum distillations inside Bavaria is cheaper than crude oil and is directly burned by 


\section{Pruckner and German}

oil power plants. Moreover, we don't consider other energy sources in our simulation model which are mentioned in official electricity generation balances. Currently, we don't model such details.

However, the validation for the years 2010 and 2011 is quite good and our simulation model can be used to investigate scenarios for Bavarian's future electricity generation system.

\section{SCENARIOS FOR LARGE-SCALED ELECTRICITY GENERATION SYSTEMS}

In this section we define four different scenarios which are of special interest for the German federal state Bavaria. We use the basic concepts and components described in previous sections. All scenarios have the following assumptions in common and are based on the Bavarian energy concept (Bavarian State Government 2011):

- Discontinuation of nuclear power plants inside Bavaria at the end of 2015, 2017, 2021, 2022.

- Constant annual electricity demand of $85 \mathrm{TWh}$.

- Modeling of all present conventional power plants inside Bavaria and age-related discontinuation of them (Dena - German Energy Agency 2012a).

- Fuel and $\mathrm{CO}_{2}$ certificate prices according to (Dena - German Energy Agency 2012b) and the knowledge of domain experts.

- Consideration of network transmission capacities for electricity imports from outside Bavaria (e.g., further federal states of Germany, Czech Republic, and Austria).

The scenarios are different with regard to the extension plans of RES (see Table 1), building of new gas power plants, and additional electricity imports from wind energy stations outside Bavaria (extension of net transmission capacities are necessary).

Table 1: Overview of the extension plans of RES

\begin{tabular}{lccccc} 
& Hydropower & Biomass & Photovoltaics & Wind Energy & Geothermal Energy \\
\hline Ref. 2010 & $13.60 \%$ & $6.70 \%$ & $4.90 \%$ & $0.64 \%$ & $<0.01 \%$ \\
\hline $40 \%$ RES 2021 & $13.60 \%$ & $9.0 \%$ & $15.0 \%$ & $3.0-5.0 \%$ & $0.50 \%$ \\
\hline $50 \%$ RES 2021 & $17.0 \%$ & $10.0 \%$ & $16.0 \%$ & $6.0-10.0 \%$ & $0.50 \%$ \\
\hline
\end{tabular}

In Table 2 the scenarios are defined. In addition, the power plant capabilities outside Bavaria are specified. In each scenario, the extension of RES is based on the year 2010 and is linearly interpolated until the aims in 2021 are reached. For the building of new gas power plants the scenario interfaces are used. For instance, new combined cycle gas turbines are built in the years 2018, 2019, and 2020 with an aggregated capability of $2400 \mathrm{MW}$ (800 MW each).

Table 2: Definition of various scenarios

\begin{tabular}{lcccccc} 
Scenario Name & RES & New Gas PP & \multicolumn{3}{c}{ PP Capabilities outside Bavaria (in GW) } \\
& (in \%) & (in GW) & Wind Energy & Lignite & Hardcoal & Nuclear \\
\hline $40 \%$ RES & 40 & - & max. 1.50 & 1.25 & 1.25 & 1.0 \\
\hline $50 \%$ RES & 50 & - & max. 1.50 & 1.25 & 1.25 & 1.0 \\
\hline New Gas PP & 50 & 3.0 & max. 1.50 & 1.25 & 1.25 & 1.0 \\
\hline Add. Wind Imports & 50 & 3.0 & max. 3.50 & 1.25 & 1.25 & 1.0 \\
\hline
\end{tabular}

\section{RESULTS}

The main goal of our simulation is to investigate the differences between the scenarios described in the last section with regard to the annual electricity generation mix, $\mathrm{CO}_{2}$ emission rates, full load hours of new gas power plants, electricity imports and exports etc. for the year 2023 - the first year without nuclear power 
in Germany. We implemented all scenarios in our simulation framework. The simulated time begins on $1 / 1 / 2010$ and ends on 31/12/2023. Each scenario was simulated fifteen times in an hourly resolution.

Figure 7 depicts some examples of simulation results for the year 2023. The electricity generation balance is shown on Figure 7 (a). The extension objectives for RES of $40 \%$ and $50 \%$, respectively, were reached in all scenarios. The remaining demand is covered by hardcoal, gas, waste, and oil power plants inside Bavaria. Moreover, electricity imports of approximately $30 \%$ are necassary to cover the demand. However, in the "40\% RES" scenario the current network transmission capacities and the Bavarian power plant fleet are not sufficient to cover the electricity demand in 2023. There is a lack of electric energy amounting to approximately $2300 \mathrm{GWh}$. In all other scenarios the electricity generation is sufficient to cover the annual demand. Nevertheless, there are many hours with a surplus or shortage on electricity noticeable.

In Figure 7 (b) the $\mathrm{CO}_{2}$ emission balance is shown. The equivalent specific $\mathrm{CO}_{2}$ emission rates, which serves as the basis for calculating the $\mathrm{CO}_{2}$ balance, can be found in (Wagner, Koch, and Burkhardt 2007). Compared to the reference year 2010, we determine an increase of the annual per-capita $\mathrm{CO}_{2}$ emission in ton for all scenarios (total population of Bavaria: 12.5 mill.). In spite of the high amount of renewables in all scenarios, the reason for the increase is the phase-out of nuclear power with very low specific $\mathrm{CO}_{2}$ emission rates. As we can see, the extension of network transmission capacities for importing more wind energy and the building of new gas power plants can help to reduce the $\mathrm{CO}_{2}$ emissions inside Bavaria.

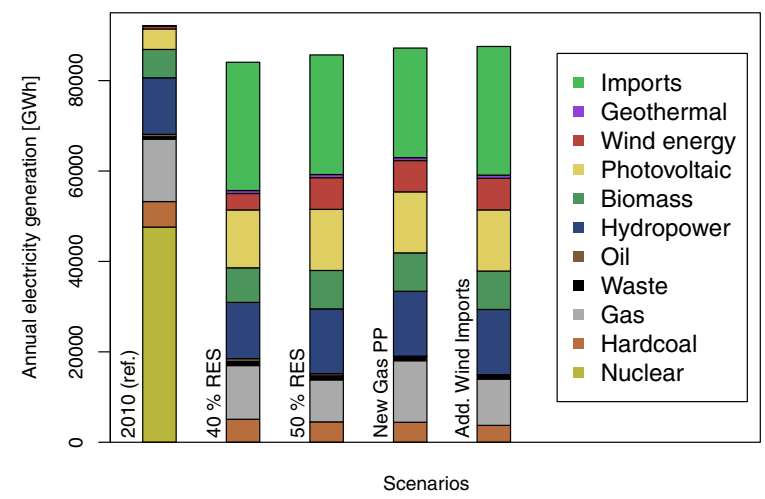

(a) Electricity generation mix

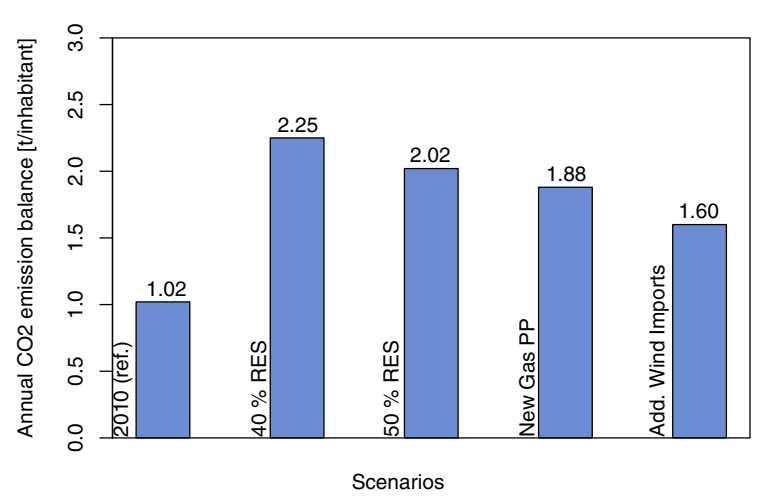

(b) $\mathrm{CO}_{2}$ emission balance

Figure 7: Simulation Results for different scenarios for the year 2023

\section{CONCLUSION AND FUTURE WORK}

In this paper we introduced a flexible and validated hybrid simulation environment - implemented in Anylogic - for electricity generation systems. The modular design and scenario interfaces allow the flexible and rapid investigation of system relevant framework conditions and their impact on the electricity generation system. We used a hybrid simulation approach with SD and DES elements. We implemented modules for the electricity demand, conventional power plants, RES, electricity storages and combined them to set up the Bavarian electricity generation system. Moreover, we validated our simulation framework for the years 2010 and 2011 with real data. For illustration purposes, we defined four different scenarios and simulated them. The results show, that the building of new gas power plants is quite important to cover possible lacks of capabilities. At the same time the $\mathrm{CO}_{2}$ emissions will increase according to our model.

Future work includes the refinement of existing models and the implementation of further components. Moreover, we are aiming to model further energy economy related topics such as new market models. Also the investigation of further scenarios and more output parameters, such as the development of electricity prices, will be covered by our research activities. Furthermore, our framework allows to consider shorter 


\section{Pruckner and German}

time periods such as days or weeks in detail. This feature is useful, e.g., to investigate and optimize the interaction with decentralized storages.

\section{ACKNOWLEDGMENTS}

This work has been conducted within the project "Energy System Analysis Bavaria" which is coordinated by Dr. Klaus Hassmann (spokesman of the Cluster Energy Technology, Bayern Innovativ, www.bayerninnovativ.de). The project is supported by the Bavarian Energy Agency, Allgäuer Überlandwerk, Areva, renerco, e.on, infra-Fürth, Kraftanlagen München, OMV, Ostwind, Siemens, SWU, Tennet, Thüga, and Verbund. The authors would like to thank Dr. Hassmann and the partners for various discussions and the providing of data.

\section{References}

Allgäuer Überlandwerk GmbH 2013, January. "Private Communications".

Australian Government 2013. "Renewable Energy Target". Accessed Apr. 5, 2013. http://climatechange. gov.au/government/initiatives/renewable-target.aspx.

Bavarian State Government 2011. "Bayerisches Energiekonzept - Energie innovativ". Accessed Mar. 28, 2013. http://www.energie-innovativ.de/energie-versorgung/.

Bazan, P., and R. German. 2012. "Hybrid Simulation of Renewable Energy Generation and Storage Grids". In Proceedings of the 2012 Winter Simulation Conference, edited by C. Laroque, J. Himmelspach, R. Pasupathy, O. Rose, and A. M. Uhrmacher. Berlin, Germany.

Blesl, M., D. Bruchof, U. Fahl, T. Kober, R. Kuder, R. Beestermöller, B. Götz, and A. Voß. 2011. "Auswirkungen veränderter Laufzeiten für Kernkraftwerke in Deutschland - Szenarioanalysen bis zum Jahr 2035”. Accessed Apr. 5, 2013. http://www.ier.uni-stuttgart.de/publikationen/arbeitsberichte/ Arbeitsbericht_10.pdf.

Bludszuweit, H., J. A. Dominguez-Navarro, and A. Llombart. 2008, August. "Statistical Analysis of Wind Power Forecast Error". IEEE Transactions on Power Systems 23 (3): 983-991.

Boulaire, F., M. Utting, R. Drogemuller, G. Ledwich, and I. Ziari. 2012. "A Hybrid Simulation Framework to Assess the Impact of Renewable Generators on a Distribution Network". In Proceedings of the 2012 Winter Simulation Conference, edited by C. Laroque, J. Himmelspach, R. Pasupathy, O. Rose, and A. M. Uhrmacher. Berlin, Germany.

Bundesnetzagentur 2013. "List of German Power Plants". accessed on March 13th, 2013.

Commission of the European Communities 2008. "20 20 by 2020 - Europe's climate change opportunity". Accessed Nov. 12, 2013. http://www.energy.eu/directives/com2008_0030en01.pdf.

Connolly, D., H. Lund, B. V. Mathiesen, and M. Leahy. 2010. "A review of computer tools for analysing the integration of renewable energy into various energy systems". Applied Energy 87 (4): 1059-1082.

Dena - German Energy Agency 2012a. "Bruttostromerzeugung in Deutschland". Accessed October 16th, 2012.

Dena - German Energy Agency 2012b. "Integration der erneuerbaren Energien in den deutsch-europäischen Strommarkt".

Djanatliev, A., R. German, P. Kolominsky-Rabas, and B. M. Hofmann. 2012. "Hybrid Simulation with Loosely Coupled System Dynamics and Agent-Based Models for Prospective Health Technology Assessments". In Proceedings of the 2012 Winter Simulation Conference, edited by C. Laroque, J. Himmelspach, R. Pasupathy, O. Rose, and A. M. Uhrmacher. Berlin, Germany.

ENTSO-E 2013. "Hourly load values of a specific country of a specific month". Accessed Jan. 22, 2013. https://www.entsoe.eu/resources/data-portal/consumption/.

Federal Ministry for the Environment, Nature Conservation and Nuclear Safety 2004. "The main features of the Act on granting priority to renewable energy sources". Accessed Mar. 28, 2013. http://www. bmu.de/files/english/pdf/application/pdf/eeg_gesetz_merkmale_en.pdf. 


\section{Pruckner and German}

German Renewable Energies Agency 2010. "Renewable Energies and Base Load Power Plants: Are They Compatible?". Renews Special 35:1-18.

Hassmann, K., M. Pruckner, and R. German. 2013. "Ratgeber und Werkzeug zur Steuerung der Energiewende". BWK - Das Energie-Fachmagazin 1/2:62-69.

Haubrich H.-J. and Consentec GmbH 2008. "Gutachten zur Höhe des Regelenergiebedarfs". Accessed Oct. 25, 2013. http://www.bundesnetzagentur.de/cae/servlet/contentblob/102556/publicationFile/5861/.

Heath, S. K., S. C. Brailsford, A. Buss, and C. M. Macal. 2011. "Cross-Paradigm Simulation Modeling: Challenges and Successes". In Proceedings of the 2011 Winter Simulation Conference, edited by S. Jain, R. R. Creasey, J. Himmelspach, K. P. White, and M. Fu, 2788-2802. Phoenix, Arizona.

International Energy Agency 2012. "World Energy Model". Accessed Apr. 5, 2013. http://www. worldenergyoutlook.org/weomodel/.

Kremers, E., N. Lewald, O. Barambones, and J. de Durana. 2009. "An Agent-based Multi-Scale Wind Generation Model". In Power and Energy Systems. Palma de Mallorca, Spain.

Ostwind Project GmbH 2012, August. "Private Communications".

Pruckner, M., P. Bazan, and R. German. 2012, September. "Towards a simulation model of the Bavarian electrical energy system". In Informatik 2012 Smart Grid Workshop.

Pruckner, M., and R. German. 2013. "A Simulation Model to Analyze the Residual Load During the Extension of Highly Fluctuating Renewables in Bavaria, Germany". In Proceedings of the International Conference on Power Engineering, Energy and Electrical Drives (Powereng 2013). Istanbul, Turkey. (to appear).

Renerco AG 2012, July. "Private Communications".

Schlesinger, M., D. Lindenberger, and C. Lutz. 2010. "Energieszenarien für ein Energiekonzept der Bundesregierung". Accessed Apr. 5, 2013. http://www.bmu.de/fileadmin/bmu-import/files/pdfs/allgemein/ application/pdf/energieszenarien_2010.pdf.

von Roon, S., and M. Huck. 2010. "Merit Order des Kraftwerkparks". Accessed Apr. 14, 2013. http: //www.ffe.de/download/wissen/20100607_Merit_Order.pdf.

Wagner, H.-J., M. Koch, and J. Burkhardt. 2007. "CO2-Emissionen der Stromerzeugung”. BWK 59 (10): $44-52$.

XJ Technologies Company Ltd. 2013. "AnyLogic Version 6". Accessed Apr. 5, 2013. http://www.xjtek.com.

Zulkepli, J., T. Eldabi, and N. Mustafee. 2012. "Hybrid Simulation for Modelling Large Systems: An Example of Integrated Care Model". In Proceedings of the 2012 Winter Simulation Conference, edited by C. Laroque, J. Himmelspach, R. Pasupathy, O. Rose, and A. M. Uhrmacher. Berlin, Germany.

\section{AUTHOR BIOGRAPHIES}

MARCO PRUCKNER is a Research Assistant at the Department of Computer Science (Computer Networks and Communication Systems) at the University of Erlangen-Nuremberg. He studied Mathematics at the University of Erlangen-Nuremberg and obtained his Master Degree (Diplom) in 2011. He is mainly interested in the analysis of the Bavarian electricity generation system based on hybrid simulation techniques. His e-mail address is marco.pruckner@cs.fau.de.

REINHARD GERMAN received a Diploma in Computer Science in 1991, the PhD degree in 1994, and the habilitation degree in 2000 from the Computer Science Department, Technical University of Berlin. Thereafter, he joined the Department of Computer Science at the University of Erlangen-Nuremberg. First, he was an Associate Professor (system simulation), then he became a Full Professor in 2004 (Computer Networks and Communication Systems), and served as head of the department and as dean of the faculty of engineering. His research interests include performance and dependability analysis of networked systems based on numerical analysis, network calculus, discrete-event simulation, measurements, and testing. Vehicular communications, smart energy systems, and healthcare constitute major application domains. His e-mail address is german@cs.fau.de. 